\title{
Review Article \\ Research Progress on Durability of Cellulose Fiber-Reinforced Cement-Based Composites
}

\author{
Jie Liu ${ }^{1}$ and Chun $\mathrm{Lv} \mathbb{1 D}^{2}$ \\ ${ }^{1}$ College of Light-Industry and Textile Engineering, Qiqihar University, Qiqihar 161006, China \\ ${ }^{2}$ College of Architecture and Civil Engineering, Qiqihar University, Qiqihar 161006, China
}

Correspondence should be addressed to Chun Lv; lvchun8603@163.com

Received 15 April 2021; Revised 26 June 2021; Accepted 31 July 2021; Published 17 August 2021

Academic Editor: Ching Hao Lee

Copyright (C) 2021 Jie Liu and Chun Lv. This is an open access article distributed under the Creative Commons Attribution License, which permits unrestricted use, distribution, and reproduction in any medium, provided the original work is properly cited.

\begin{abstract}
The performance of cellulose fiber-reinforced cement-based composites (CFCCs) depends not only on the characteristics of the cement matrix and fibers but also on the bonding property of the matrix and fibers. The durability of cement-based composites including various properties such as impermeability, frost resistance, and carbonization resistance has an important impact on the long-term service life of the matrix structure. The presence of a large number of hydroxyl groups on the molecular chain of cellulose can promote the formation of intra- and intermolecular hydrogen bonds of cellulose. This special structure imparts the cellulose high hydrophilicity, which leads the cement hydration C-S-H gel to adhere to the surface of cellulosic fibers (CFs) and induce its growth. The cavity of CFs has good water absorption and can be used as an internal curing fiber for the continuous hydration of cement-based composites. But CFs in the Portland cement matrix tend to deteriorate under strong alkali conditions. This paper presents a review of the research on the durability of CFCCs. The methods and paths to improve the durability of CFCCs are summarized and analyzed from the perspectives of the internal curing of CFs, the deterioration of the performance of CFs in the matrix, and the use of many types of supplementary cementitious materials. Finally, the development and engineering application of CFCCs have been prospected.
\end{abstract}

\section{Introduction}

In the last few years, more and more different types of fibers have been used to reinforce cement-based composites. As is known, these fibers include steel, organic synthetic, carbon, and glass fibers. The commonly used fibers for reinforcements exhibit a set of advantages, such as long application time, relatively mature technology, and interesting physical and mechanical properties. However, compared to CFs, the commonly used fibers have their own limitations [1]. As far as we know, the density of steel fibers is relatively large, which cannot meet the requirements of reducing the weight of composites. At the same time, the size of the steel fiber is too large, there is an interface transition zone in the cement matrix, and it also lacks inducing the growth of the hydrate gel in the cement matrix interface transition zone. The organic synthetic fiber has poor compatibility with the cement matrix and is not easy to disperse in the cement matrix. It pollutes the environment greatly, which is contrary to the concept of green cement-based composites [2-4]. The carbon fiber is easy to agglomerate in the cement matrix, and the cost is relatively high [5-8]. The glass fiber is brittle and has poor wear resistance $[9,10]$.

Plant fibers such as crop straws are composed of cellulose, hemicellulose, lignin, and other substances, and cellulose is the main component. CFs are widely found in nature. They are inexpensive, have low density, are renewable, are biodegradable, are rich in sources, and have good reinforcement effects on cement-based composites [11-13]. The geometric characteristics, mechanical properties, volume mixing ratio of $\mathrm{CFs}$, and bonding property of the fiber and matrix interface are important factors that affect the strength and toughness of the matrix. Compared with traditional fibers, CFs have a larger specific surface area, aspect ratio, excellent toughness, and bonding ability. It disperses evenly in the cement matrix, has good compatibility, and has a filling and bridging effect on the cement matrix [14]. At the same time, the addition of CFs also greatly reduces the density of cement-based 


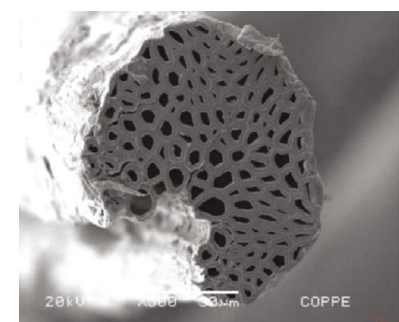

(a)

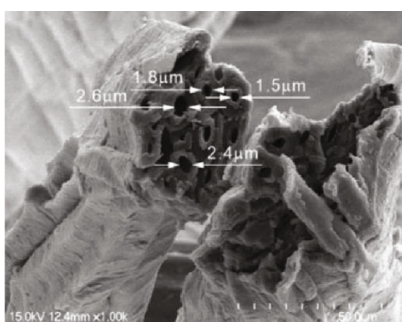

(b)

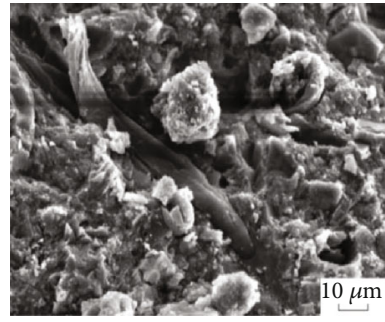

(c)

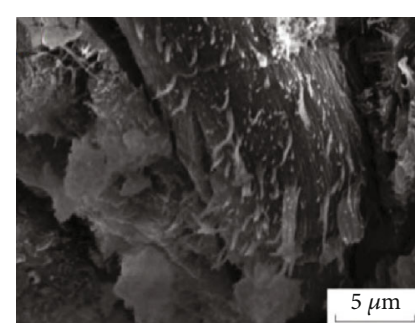

(d)

Figure 1: SEM images of CFs. (a) Sisal fibers [39]. (b) Jute fibers [13]. (c, d) Combination of the macroscale fiber and cement matrix [37].

composites, improves their flexural strength [15-17], inhibits the occurrence and development of microcracks within the matrix $[18,19]$, and enhances the impact resistance of cement-based composites [20].

Over the last few years, studies on the toughening modification of cement-based composites using CFs have focused on the macromechanical properties of composites, the microstructure of the interface between the cement matrix and the fibers, the effect of fiber cracking and toughening, and the durability [21-24]. The durability of cement-based composites includes impermeability, frost resistance, carbonization resistance, and resistance to sulfate attack, which have an important impact on the long-term service life of the structure [25]. The durability of CFCCs is the main reason which limits their engineering application [26].

This paper presents a review of the research done in the area of the durability of CFCCs during the last years (2005.01-2021.05), which used Chinese journal literature retrieval databases, including China Journal Network and CNKI Scholar, English journal literature retrieval databases, and so on. Search keywords include cellulose fiber, concrete durability, internal curing, impermeability, frost resistance, and carbonization. In the searched literature, no relevant similar reviews have been found, and works of literature that are not related to the content of the paper have also been excluded. Only a few book chapters or reviews provide a general overview of the durability of CFCCs [27, 28], summarizing the main improvements and findings from a few research papers. There are also overviews of nanocellulose fibers, which are different from the contents discussed in this paper $[29,30]$. The durability of CFCCs such as impermeability, frost resistance, and carbonization resistance is reviewed, and the impact of CFs on the durability of composites and the internal curing of CFs is discussed in this paper. From the perspectives of the performance, the degradation of CFs in the matrix, and the application of multiple types of auxiliary gel materials, a summary analysis is made to improve the durability of CFCCs, and the solutions are proposed.

\section{Performance of CFs}

As one of the most abundant renewable resources, CFs have the advantage of being low cost and environmentally friendly [31]. In 1932, scientists studied the chemical structure of cellulose [32]. Cellulose is a straight-chain polymer formed by linking countless D-glucopyranose anhydrides(1-5) with $\beta(1-4)$ glycosides. The structure of cellulose is highly regular and unbranched, and the chemical formula is $\left(\mathrm{C}_{6} \mathrm{H}_{10} \mathrm{O}_{5}\right)_{n}$. There are a large number of hydroxyl groups on the molecular chain of cellulose. The presence of this polar group promotes the formation of intra- and intermolecular hydrogen bonds of cellulose [33, 34]. CFs can be made from renewable resources such as straw, they have a porous cell structure, and their specific surface area is better than other fibers [35]. As described above, there are many pores in the cross-section of the fibers, as shown in Figures 1(a) and 1(b). The properties of CFs mainly depend on the type of cellulose. The cellulose content of different types of plants varied greatly, among which the cellulose content of cotton is the highest. Table 1 shows the performance index data of commonly used CFs and other commonly used fibers [36]. The physical and mechanical properties of CFs can be seen in Table 1 . The mechanical properties of CFs such as tensile strength and Young's modulus are weaker than those of the commonly used fibers such as carbon fiber and aramid fiber. Flax, jute, ramie, sisal, and hemp fibers have better mechanical properties as similar to glass fiber in tensile strength and Young's modulus, so they can be directly used as CFCCs.

The performance of CFCCs includes working performance, mechanical properties, and durability. The effect of CFs on the working performance and mechanical properties of composites is similar to that of traditional fibers, but the impact on durability is very different. As mentioned above, the existence of a large number of hydroxyl groups on the molecular chain of cellulose promotes the formation of intraand intermolecular hydrogen bonds of cellulose. This special structure renders the cellulose extremely hydrophilic, makes the CFs compatible with the cement matrix, and has a good cohesive force. C-S-H gel, the main hydration product of the cement, grows on the surface of CFs, as shown in Figures 1(c) and 1(d). Wu et al. [37] analyzed the SEM (Figures 1(c) and 1(d)) and found that the cement hydration around CFs was more complete. The reason is that the CFs can induce the orderly and directional growth of hydration products in the initial stage of cement hydration. After the cement hardens, when the load exceeds its cracking load, the fibers can share the load, which greatly increases the load of the cement matrix, avoiding or delaying the growth of microcracks. In Figure 1(d), the CF surface has peeled off and separated countless microfibers with a diameter less than $1 \mu \mathrm{m}$. Some of the microfiber ends are embedded in the cement hydration product. The formation of the 
TABle 1: Performance of CFs and commonly used fibers.

\begin{tabular}{lcccc}
\hline Fibers & Density $\left(\mathrm{g} / \mathrm{cm}^{3}\right)$ & Elongation $(\%)$ & Tensile strength $(\mathrm{MPa})$ & Young's modulus $(\mathrm{GPa})$ \\
\hline Cotton fiber & $1.5-1.6$ & $7.0-8.0$ & $287-597$ & $5.5-12.6$ \\
Jute fiber & 1.3 & $1.5-1.8$ & $393-773$ & 26.5 \\
Flax fiber & 1.5 & $2.7-3.2$ & $345-1035$ & 27.6 \\
Ramie fiber & 1.5 & $3.6-3.8$ & $400-938$ & $61.4-128.0$ \\
Sisal fiber & 1.5 & $2.0-2.5$ & $511-635$ & $9.4-22.0$ \\
Coir fiber & 1.2 & 30.0 & 175 & $4.0-6.0$ \\
Cork fiber & 1.5 & - & 1000 & 40.0 \\
E-glass fiber & 2.5 & 2.5 & $2000-3500$ & 70.0 \\
S-glass fiber & 2.5 & 2.8 & 4570 & 86.0 \\
Aramid fiber & 1.4 & $3.3-3.7$ & $3000-3150$ & $63.0-67.0$ \\
Carbon fiber & 1.4 & $1.4-1.8$ & 4000 & $230.0-240.0$ \\
\hline
\end{tabular}

TABle 2: Performance of CFs and commonly used fibers.

\begin{tabular}{lccccc}
\hline CFs & Length $(\mathrm{nm})$ & Diameter $(\mathrm{nm})$ & Tensile strength (MPa) & Young's modulus (GPa) & Ref. \\
\hline Macroscale CFs (cotton) & $2,000,000-3,000,000$ & 11,540 & $287-597$ & $5.5-12.6$ & {$[36]$} \\
Microcrystalline CFs & $100-3,000$ & 1,440 & 7,500 & $100.0-140.0$ & {$[37,40,41]$} \\
Nanocrystalline CFs & $50-500$ & $1-100$ & & & \\
\hline
\end{tabular}

microstructure of the cement paste will be accompanied by complex chemical reactions and physical changes. When the shrinkage of the matrix is restricted, the cement-based material will crack. The degree of cracking depends on the tensile strength and shrinkage stress of the cement paste. These microfibers play a bridging and filling role in the composites. The moisture absorbed in the CFs supplements the lack of moisture in the cement hydration process and can induce the hydration of the cement surface, and the hydration product can fill the microcracks so as to achieve the composites' effect of enhancing impermeability.

However, the lignin and hemicellulose in CFs are easily dissolved in the alkaline solution of the cement matrix, and the strong alkali material enters the fiber cavity to cause the mineralization and degradation of the fiber structure, thereby affecting the durability. The CFs applied to cement-based composites can be classified by the function of their size. CFs can be found as macroscale, microcrystalline, and nanocrystalline CFs. Macroscale CFs include strands (long fibers of lengths around 20 to $100 \mathrm{~cm}$ ), staple fibers (short fibers with lengths between 1 and $20 \mathrm{~cm}$ ), and pulp (very short fibers with lengths between 1 and $10 \mathrm{~mm}$ ), which can be processed by chemical methods to form micron-scale microcrystalline CFs and nanosized nanocrystalline CFs [37, 38].

In general terms, micron-sized microcrystalline $\mathrm{CFs}$ and nanosized nanocrystalline CFs can be produced in chemical or enzymatic ways. The loosely arranged amorphous regions in the cellulose are destroyed, and the crystalline regions are retained to obtain micron-sized microcrystalline CFs and nanosized nanocrystalline CFs with higher crystallinity. The preparation methods of nanocrystalline CFs mainly include the physical mechanical method, acid hydrolysis method, and biological method. Nanocrystalline CFs have a rigid rod-like structure, and their properties are shown in Table 2.

\section{Research Status of Durability of CFCCs}

Anselme Payen, a French scientist, extracted a compound from wood in 1838 and named it cellulose. The majority of the fabrication methods for cement composites reinforced with CFs in the pulp form are based on the Hatschek process, patented by L. Hatschek in 1900 [27]. After a century, the research and application of CFCCs have become increasingly widespread. The research on CFs is from mechanical property to durability, from the bonding phenomenon between the CFs and the matrix to the bonding mechanism, and from macroscale application to microscale application. Only a few studies have been focused on the bond adhesion of CFs with cement matrices. For instance, some studies analyzed the effect of CF shape and curing age on the bond strength of CFCCs using pull-out tests [28, 42], and the other studies analyzed the fiber matrix bond adhesion indirectly [14-16].

At this stage, research studies on the durability of CFCCs include frost resistance, carbonization resistance, water penetration resistance, chloride ion penetration resistance, gas penetration resistance, sulfate erosion resistance, early anticracking performance, compressive creep performance, and compressive fatigue deformation performance. In general terms, the durability of the composites depends on the resistance to chloride ion permeability, frost resistance, and carbonization resistance. As can be seen in Table 3, it is a summary of related studies on the durability of CFCCs.

Table 3 shows that CFCCs are rich in varieties, and their durability involved a wide range, which are closely related to the service life of the composites. The test methods for resistance of CFCCs to freezing and thawing usually include slow freezing and thawing, rapid freezing and thawing, and singleside freezing and thawing. The test methods for resistance of CFCCs to chloride penetration adopt the rapid chloride 
TABle 3: Summary of studies on durability of CFCCs.

\begin{tabular}{|c|c|c|c|c|c|c|}
\hline Durability & CFs & CFs (wt.\%) & Fiber form & Cementitious & Test methods & Ref. \\
\hline \multirow{2}{*}{$\begin{array}{l}\text { Antichloride ion } \\
\text { penetration }\end{array}$} & UF500 CF & $0.45 \sim 1.5$ & \multirow[t]{2}{*}{ Randomly dispersed } & P.O42.5 & $\begin{array}{l}\text { RCM method; water } \\
\text { seepage hight }\end{array}$ & [43-45] \\
\hline & Bokai super fiber & $0.6 \sim 1.2$ & & P.O52.5 & Water seepage pressure & [46] \\
\hline Antifreezing & $\begin{array}{l}\text { Flake fiber } \\
\text { UF500 CF }\end{array}$ & $\begin{array}{c}0.9 \\
0.1 \sim 0.2\end{array}$ & Randomly dispersed & P.O42.5 & Rapid freezing & $\begin{array}{c}{[43,47]} \\
{[48]}\end{array}$ \\
\hline Carbonization & $\begin{array}{l}\text { Cork kraft pulp } \\
\text { Rape straw fiber } \\
\text { Coir fiber }\end{array}$ & $\begin{array}{c}8.0 \\
0.5 \sim 2.00 \\
2.0\end{array}$ & Randomly dispersed & $\begin{array}{c}\text { P.II42.5R } \\
\text { SAC } \\
\text { Slag cement }\end{array}$ & Accelerate carbonization & $\begin{array}{c}{[49]} \\
{[50,51]} \\
{[52]}\end{array}$ \\
\hline Antidry and wet cycle & $\begin{array}{l}\text { Sisal fiber } \\
\text { Cork CF } \\
\text { Sisal fiber }\end{array}$ & $\begin{array}{c}1.5 \sim 8.0 \\
4.0 \\
0.6\end{array}$ & Randomly dispersed & $\begin{array}{c}\text { P.O42.5R } \\
\text { P.O42.5 } \\
\text { Calcined clay }\end{array}$ & $\begin{array}{c}\text { CBI method } \\
25 \mathrm{dry} / \text { wet cycles } \\
100 \mathrm{dry} / \text { wet cycles }\end{array}$ & $\begin{array}{c}{[53,54]} \\
{[55]} \\
{[56]}\end{array}$ \\
\hline Antisulfate attack & UF500 CF & 0.9 & Randomly dispersed & P.II42.5R & Sulfate-wet and dry cycle coupling & [51] \\
\hline Anticrack & Sisal fiber & 2.0 & Aligned & $\mathrm{MK} / \mathrm{PC}$ & Instron 5948 test system & [57] \\
\hline
\end{tabular}

migration (RCM) coefficient test and coulomb electric flux test. The procedures for preparing CFCCs reported in the literature can be divided into two main groups depending on the fiber form: fibers randomly dispersed in the cement matrix [58-60] and aligned fibers or fibrous structures [43, $46,50,53]$. In view of the fibers randomly dispersed in the matrix, it has certain limitations in the mechanical properties of reinforced composites, and aligned fibers or fibrous structures are also used to strengthen the cement matrix $[49,56,57,61]$.

Cement-based composite is a kind of porous material, which provides a channel for harmful external impurities to penetrate into the matrix. Adding CFs to the cement matrix can reduce the generation of early microcracks, inhibit the development of microcracks during the service period of the matrix, and improve the durability of CFCCs. After absorbing water, the CFs are evenly dispersed into the cement matrix, forming a plurality of microwater flow channels inside the matrix. These pores can continue to provide water for the later cement hydration, make it fully hydrated, ensure the mechanical properties of the cement matrix, prevent the cement matrix from cracking, and also improve the cement matrix's antipermeability, antifreezing, and anticarbonization capabilities. The uniform distribution of the fiber network enhances the adhesion between the matrix components, the matrix structure has good integrity, and the impact resistance is also significantly improved [62].

3.1. Impermeability of CFCCs. Impermeability is an important factor that affects the durability of CFCCs. CFs are evenly distributed in the cement matrix, which can reduce the segregation effect in the initial stage of the cement hydration, inhibit the formation of shrinkage cracks in the cement matrix, reduce the porosity of the matrix, improve the compactness of the matrix, and effectively prevent harmful substances from penetrating into the matrix. It is usually determined by the rapid chloride ion migration coefficient test or the water penetration height test [44]. The chloride ion diffusion coefficient and the water penetration height are reduced after the CFs have been mixed, and the imperme- ability of the CFs is better than that of the polypropylene fibers under the same dosage. The test results showed that when the CF volume fraction was $0.9 \%$, the effect of improving the impermeability of the matrix was the best [45]. CFs have little effect on the compressive strength of the matrix but significantly improve the splitting tensile strength, axial tensile strength, and ultimate tensile value and effectively block the penetration of chloride ions. At the same time, the cracking time and the width of the matrix crack have been improved $[63,64]$. It has been found through experiments that the bubble content in the $\mathrm{CF}$ cement matrix decreases by $40 \%$, and the bubble spacing becomes smaller [65].

CFs are effectively bonded to the cement matrix and distributed in random directions, forming a uniform support system, optimizing the pore structure of the cement matrix, and blocking the internal communication channels of the matrix. Due to the toughening and cracking resistance of $\mathrm{CFs}$, the number of initial cracks can be significantly reduced, the long-term cracks of the matrix can be effectively inhibited, and the possibility of forming through cracks in the matrix can be reduced. In this way, the microcrack pattern of the cement-based composite is further refined, and its impermeability is significantly improved.

3.2. Effect of Freeze-Thaw Cycles on the Durability of CFCCs. Due to the effect of negative temperature, the water in the pores of CFCCs in a water-saturated state freezes and produces a volume change to form tensile stress. Under the action of the freeze-thaw cycle, the cement matrix damage gradually accumulates and expands, which will eventually lead to the destruction of the cement matrix. CFs can significantly improve the frost resistance of CFCCs. On the one hand, the addition of CFs reduces the water penetration in the cement matrix. On the other hand, the CFs can absorb parts of the unfrozen free water and reduce the hydrostatic pressure in the cement matrix. A large number of comparative tests have shown that polypropylene fibers and CFs have improved frost resistance to cement-based composites $[47,66,67]$, and CFs are better than polypropylene fibers. 


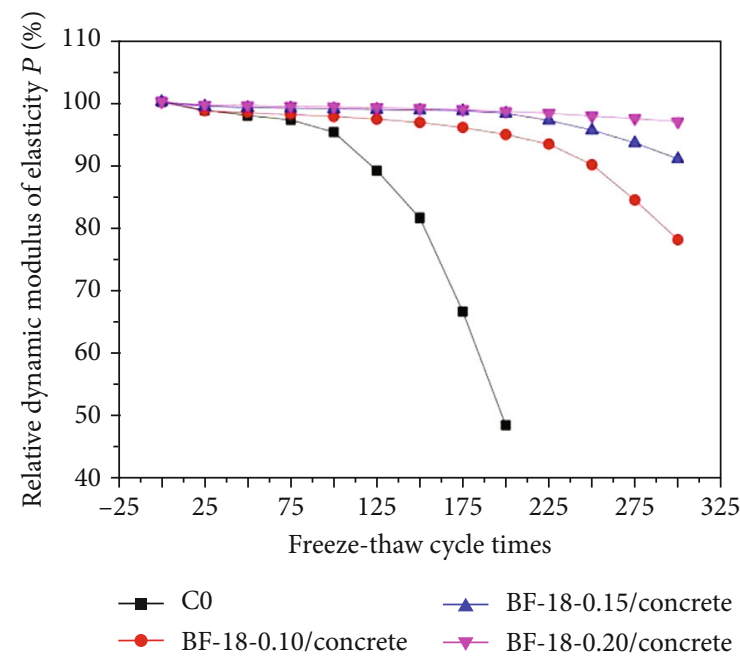

(a)

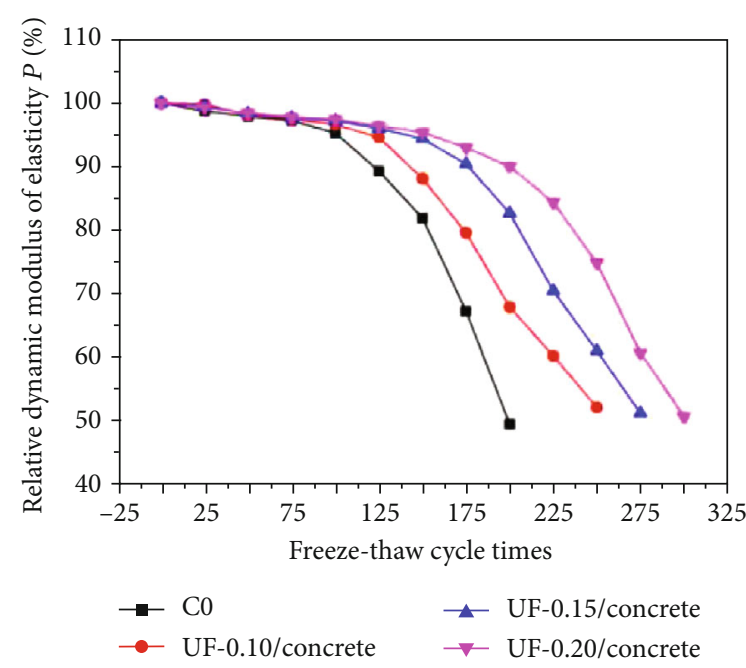

(b)

Figure 2: (a) The relative dynamic elastic modulus of basalt fibers and (b) CF with different fiber volume fraction changes with the number of freeze-thaw cycles [48].

When the volume fraction of CFs is $0.9 \%$, the antifreezing effect of CFCCs is the best. Under the action of the freezethaw cycle, the CFs have the effect of binding the surface slurry of the matrix, and its appearance damage is improved to a certain extent.

The addition of CFs slows down the rate of decrease of relative dynamic elastic modulus, increases the number of freeze-thaw cycles that the test piece can withstand, and improves the frost resistance of the CFCCs; it can be seen from Figure 2 [48]. As the number of freeze-thaw cycles increases, the relative dynamic elastic modulus of the specimens decreases. At the beginning of the freeze-thaw cycle (within 100 freeze-thaw cycles), for basalt fibers and CFs, when the fiber volume fraction is $1.0,1.5$, or $2.0 \%$, the relative dynamic elastic modulus decreases slowly, and the effect of fiber content is not much different. In the late freeze-thaw period (the number of freeze-thaw cycles is greater than 100), the decline rate increases, indicating that the internal damage of the concrete gradually increases after the freezethaw cycle. The relative dynamic elastic modulus of plain concrete decreases faster than that of fiber concrete. When the freeze-thaw cycle reaches 200 times, the freeze-thaw damage rate is far less than $60 \%$. However, the relative dynamic elastic modulus of fiber-reinforced concrete with a fiber volume fraction of $2 \%$ decreases more gently than that of concrete with fiber volume fractions of $1.0 \%$ and $1.5 \%$.

Since the elastic modulus and tensile properties of basalt fibers are higher than those of CFs, the basalt fibers can more effectively improve the tensile strength of concrete, inhibit the expansion of internal cracks in concrete, reduce the entry of water into the matrix, and delay the frost heave damage of the internal structure. Therefore, when the number of freezethaw cycles is high, basalt fibers improve the freeze resistance of concrete more significantly than CFs. In general, the effect of improving the frost resistance is not significant when the fiber volume fraction is increased from $1.5 \%$ to $2.0 \%$. Therefore, it is more economical and reasonable to choose the fiber volume fraction of $1.5 \%$.
3.3. Effect of Carbonization on the Durability of CFCCs. When CFCCs are applied as the protective layer of steel bars, the impact of carbonization on the steel bars must be paid attention to. The high alkalinity inside the matrix passivates the surface of the steel bar, and the passivated film can prevent the steel bar from corroding by the external environment. The hydration product of cement-based composites has stable performance in an alkaline environment and can maintain good cementing ability. Carbonization is the process of neutralizing the cement matrix, which can reduce the alkalinity of CFCCs and can induce the corrosion of the stressed steel bars and the destruction of the structure [68, 69]. The essence of carbonization is the diffusion process of carbon dioxide gas from the surface to the inside of the matrix. Both compactness of the matrix structure and internal defects affect the diffusion rate. The hydrophilicity and unique hollow structure of CFs optimize the pore structure of cement-based composites, which reduce internal defects and enhance carbonization resistance. In the case of loading, the generated microcracks become channels for the diffusion of carbon dioxide gas, which reduce its anticarbonization performance. After adding CFs to the matrix, the carbonization of cement-based composites is still a diffusiondominated process [70-72].

Analysis of the pore size distribution data obtained based on the mercury intrusion experiment method shows that the fiber has a significant influence on the microstructure of cement-based composites [73]. After the fiber volume fraction reaches $0.6 \%$, it can be observed that the unimodal width on the pore distribution curve of cement-based materials increases, and the number of large-scale pores (radius greater than or equal to 200 nanometers) increases, which confirms that the micromatrix structure is coarsened due to the introduction of fibers. The addition of fibers can change the working performance of the fresh cement paste, thereby producing an air-entraining effect [74]. At the $0.6 \%$ fiber volume fraction, the effect of this phenomenon exceeds the internal curing effect, which causes the degradation of the 


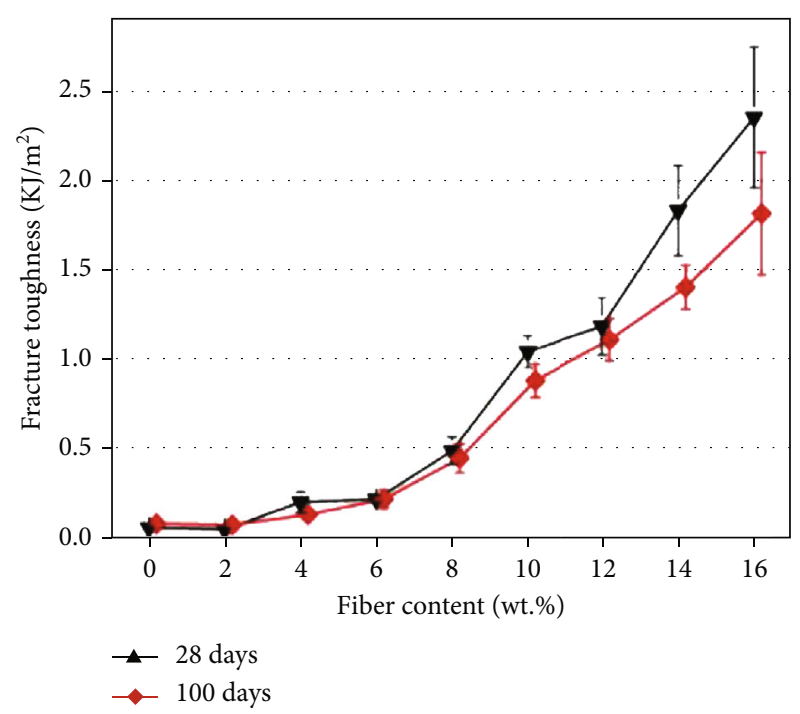

(a)

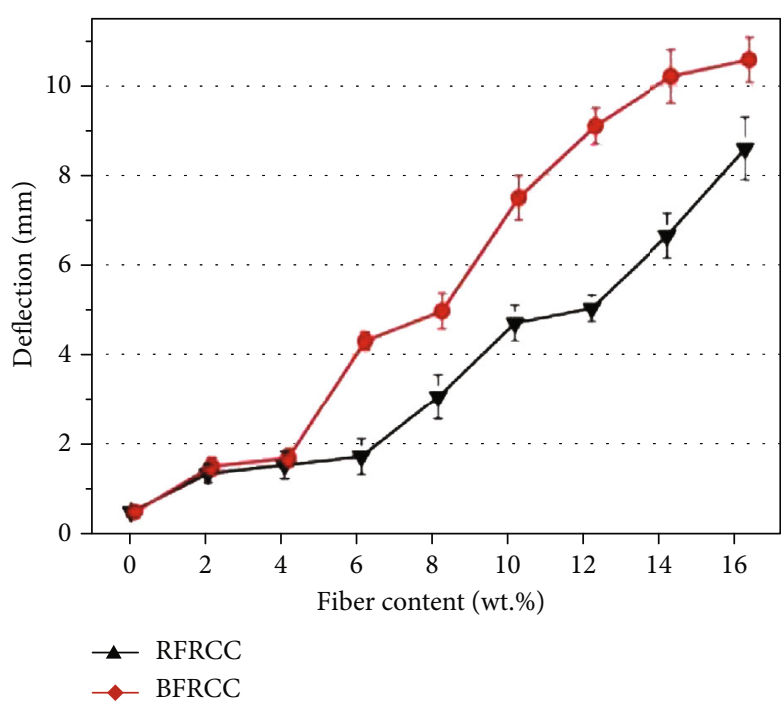

(b)

Figure 3: (a) Influence of fiber content on fracture toughness and (b) influence of fiber content on composite deformation [78].

TABLE 4: Bulk density of CFCCs at 28 days $\left(\mathrm{g} / \mathrm{cm}^{3}\right)$.

\begin{tabular}{lccccc}
\hline CFs & & \multicolumn{3}{c}{ Fiber content (wt.\%) } & 12 \\
\hline RFRCC & $2.01 \pm 0.04$ & $1.70 \pm 0.01$ & $1.49 \pm 0.03$ & $1.38 \pm 0.04$ & $1.26 \pm 0.01$ \\
BFRCC & $2.01 \pm 0.04$ & $1.71 \pm 0.01$ & $1.50 \pm 0.04$ & $1.36 \pm 0.04$ & $1.30 \pm 0.05$ \\
\hline
\end{tabular}

overall microstructure of cement-based composites. Compared with the $0.6 \%$ fiber volume fraction, at the $0.3 \%$ fiber volume fraction, the pore size distribution before and after carbonization is less different, indicating that the $0.3 \%$ fiber volume fraction has a limited effect on the microstructure of cement-based composites.

\section{Constitutive Relationship between CFs and Composite Durability}

According to the fiber spacing theory proposed by the concept of fiber crack resistance, the use of densely spaced fibers as a crack barrier can reduce the stress intensity factor of the microcrack tip inside the matrix and inhibit the propagation of microcracks in the matrix, thereby improving the initial cracking strength of the composites. It is known from the previous studies that there is a certain limit on the amount of $\mathrm{CF}$, which has a significant impact on the durability of composites due to the internal curing of the cement matrix and the long-term alkaline environment.

In fact, CFs increase the air content of the concrete and relieve the hydrostatic pressure and osmotic pressure during low-temperature cycles. Secondly, dense microfibers improve the internal quality of the concrete, reduce internal defects, and improve concrete's tensile properties such as ultimate tensile strain and fracture energy. In addition, due to the small diameter of CFs and the large number of fibers per unit weight, the fiber spacing is small, which increases the energy loss during the concrete damage process and effectively inhibits the cracking of the concrete.

4.1. Internal Curing Fiber of Cement-Based Composites. Different from other types of fibers, CFs have a unique hollow lumen structure and good water absorption. It can be used as the internal curing fiber of cement-based composites, as shown in Figures 1(a) and 1(b). In the absence of an external water supply for maintenance, it can play its role in the internal maintenance of the cement matrix, improve the water loss of the cement matrix under natural conditions, and promote continuous hydration for a long time. Therefore, its later strength increases greatly $[75,76]$. CFs can also harmonize the workability of composites and improve construction performance. In addition, the use of the curing properties of CFs can improve the interlayer deposition and stacking process of $3 \mathrm{D}$ printed cement-based composites, reduce interlayer voids and longitudinal defects, and enhance durability [77].

CFs can effectively reduce the shrinkage of the cement matrix and significantly improve the flexural strength and fracture toughness of composites. The 28-day fracture toughness and 100-day fracture toughness of the composite vary with the fiber content, as shown in Figure 3(a). The physical parameter of CFCCs varies with fiber content. As the amount of CFs increases, the density of the composites decreases. Table 4 shows the density of CFCCs [78]. When the fiber content is $16 \%$ by mass, the 28 -day fracture toughness is increased by 37 times. Figure 3(b) shows the relationship 


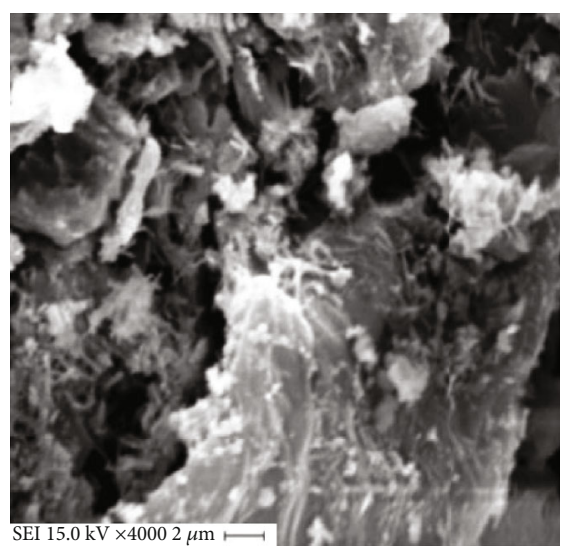

(a)

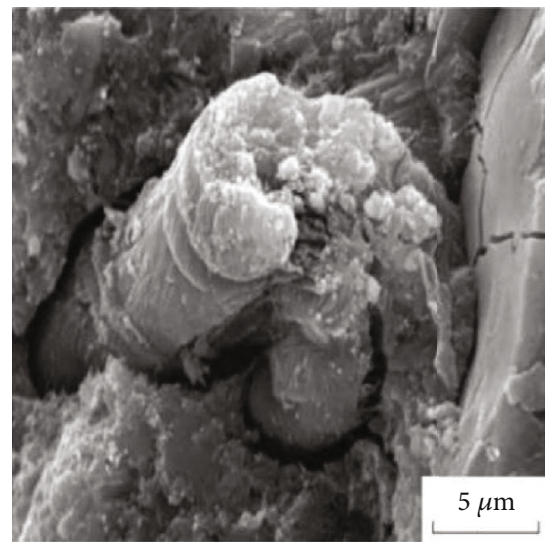

(b)

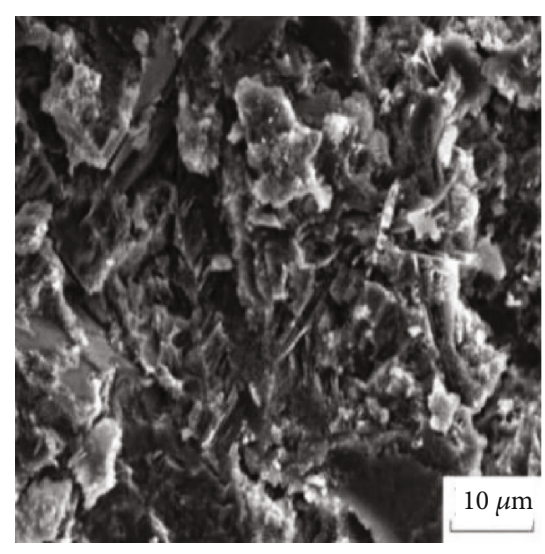

(c)

Figure 4: (a) Microstructure [72]. (b) Voids around the CFs. (c) Micro-nano-level microcrystalline cellulose [35].

between the deflection and the fiber content of two CFCCs of rice straw (RFRCC) and bamboo (BFRCC) [78]. It can be seen that as the CF content increased, the deflection of the test piece also increased, which further shows that the fiber improved the deformability and toughness of the composite, thereby enhancing the durability of the composites. As shown in Figure 3, composites reinforced with CFs experience a significant reduction in fracture toughness along with the prolongation of time. This means that the CF-reinforced composites will become stiffer and more brittle with time. Melo Filho and his coworkers [39] suggested that the weakening of energy absorbability of the CF was probably due to the deposition of calcium hydroxide crystals on the CF surface.

4.2. Deterioration of CFs in the Cement Matrix. The structural characteristics of CFs are the root cause of their deterioration in the environment of a high alkaline cement matrix. Studies have shown that the fiber is in an alkaline environment for a long time, and the lignin and hemicellulose in fibers are easy to dissolve in the alkaline solution of the cement-based composite, resulting in partial fiber breakage and tensile strength weakening. On the other hand, the strong alkali substance of the cement matrix enters into the fiber cavity to cause the mineralization of the fiber structure, which can reduce the mechanical properties of the fiber. At the same time, the extremely strong hydrophilicity of CFs causes its volume to change, which affects the overall structure durability $[49,57]$. The sisal fiber and coconut husk fiber were immersed in a calcium hydroxide-saturated solution, the strength test was conducted for 28 days, and it was found that the tensile strength decreased by about 50\% [52]. When CFs are immersed in water, saturated lime water, and sodium hydroxide solution, the lignin, cellulose, and hemicellulose contents of the fibers are all reduced $[37,58]$. The application of these deteriorated fibers in cement-based composites will inevitably cause the mechanical properties of cement-based composites to decrease.

4.3. Ways to Improve the Durability of CFCCs. At present, there are generally two methods to improve the durability of CFCCs based on the internal curing and prone to deterioration characteristics of CFs. One method is to modify the cement matrix to consume the calcium hydroxide content of the alkaline component produced during cement hydration. Another method is to modify the fibers to improve the stability of the fibers in the cement matrix by physical or chemical methods.

4.3.1. Modification of the Cement Matrix. The reinforced concrete structure should be prevented from carbonization, and as for cement-based composites reinforced with single CFs, carbonization needs to be accelerated in order to enhance their durability. The purpose of carbonization is to make the cement hydration product calcium hydroxide react with carbon dioxide to form calcium carbonate. Pizzol et al. [79] have done the strengthened and accelerated carbonization test of the composite with sisal and kraft pulp, which increased the load-bearing capacity of the composite by $25 \%$ and the toughness by $80 \%$, and reduced the fiber degradation in the cement medium. Carbonization reduced the porosity, water absorption, and nitrogen permeability of the composite, increased the matrix interface density, and made the fiber and cement matrix bond tighter, as shown in Figure 4(a). Carbonization improved the compressive strength and the durability and weather resistance of the composites, and their service life was extended [70, 71, 80]. Due to the chemical stability of the carbonized product and its reduced capillary porosity, the CFCCs have better flexural strength and can improve the adhesion between the cementbased matrix and the CFs.

Studies have shown that the optimal water content of the carbonized matrix is $40 \%$ to $60 \%$ [72], and carbonization significantly improves the durability of the matrix against dry and wet freezing and thawing. Both carbonization and the addition of mineral admixtures can reduce the calcium hydroxide content in the cement matrix. The cement-based composite is mixed with mineral admixtures such as silica fume, metakaolin, blast furnace slag, and fly ash, which can undergo secondary hydration reaction with calcium hydroxide in the cement to obtain hydrated calcium silicate or hydrated calcium aluminate [81]. Replacing part of cement 
TABLE 5: Use of supplementary cementitious materials of CFCCs.

\begin{tabular}{|c|c|c|c|c|}
\hline $\begin{array}{l}\text { Cementitious } \\
\text { materials }\end{array}$ & Weight of cement (\%) & CFs & Extent of improvement & Ref. \\
\hline MK & $50 \mathrm{MK}$ & Sisal & $\begin{array}{l}\text { Significant reduction of the calcium hydroxide } \\
\text { formation; no signs of fiber degradation }\end{array}$ & {$[38,64,83]$} \\
\hline $\mathrm{MK}$ and SF & $15 \mathrm{SF}$ or $15 \mathrm{MK}$ & Sisal & $\begin{array}{l}\text { Improved the mechanical properties and the } \\
\text { durability }\end{array}$ & {$[81]$} \\
\hline SL, SF, and MK & $70 \mathrm{SL} / 10 \mathrm{MK}$ or $70 \mathrm{SL} / 10 \mathrm{SF}$ & Kraft pulp & Effective in preventing degradation & {$[82]$} \\
\hline RHA, MK, and NC & $30 \mathrm{RHA}, \mathrm{MK}$, and $\mathrm{NC}$ & Sisal & $\begin{array}{l}\text { The durability of composites was improved owing } \\
\text { to the mitigation of fiber degradation }\end{array}$ & {$[53]$} \\
\hline SF and SL & $10 \mathrm{SF}$ and $40 \% \mathrm{SL}$ & Cannabinus & Slowing down the strength loss and embrittlement & {$[84]$} \\
\hline SF, SL, FA, MK & $\begin{array}{l}10 \% \mathrm{SF} / 70 \% \mathrm{SL}, 10 \% \\
\mathrm{MK} / 70 \% \mathrm{SL} \text {, and } 10 \% \\
\mathrm{MK} / 10 \% \mathrm{SF} / 70 \% \mathrm{FA}\end{array}$ & $\begin{array}{l}\text { Softwood kraft } \\
\text { pulp }\end{array}$ & $\begin{array}{l}\text { Prevented composite degradation due to a reduction } \\
\text { in the calcium hydroxide content and the stabilization } \\
\text { of the alkali content }\end{array}$ & {$[85]$} \\
\hline SL, GY, LI & 88 SL/10 GY/2 LI (0 cement) & Coir and sisal & $\begin{array}{l}\text { Do not appear to have a significant effect on the } \\
\text { prevention of ductility dropping }\end{array}$ & {$[86]$} \\
\hline SF, NRL & $13.55 \mathrm{SF} / 14.55 \mathrm{CF} / 1.40 \mathrm{NRL}$ & Cellulose & Improved material durability & {$[20]$} \\
\hline
\end{tabular}

TABLE 6: Modification of CFs and the extent of improvement.

\begin{tabular}{|c|c|c|c|c|}
\hline Type & Method & CFs & Extent of improvement & Ref. \\
\hline \multirow[b]{2}{*}{ Physical modification } & Polyelectrolyte adsorption & Blue eucalyptus paper & Antibacterial effect & {$[91]$} \\
\hline & Nonelectrolyte adsorption & Cellulose nanocrystals & $\begin{array}{l}\text { Changed the surface structure and properties } \\
\text { of cellulose }\end{array}$ & [92] \\
\hline \multirow{3}{*}{$\begin{array}{l}\text { Chemical } \\
\text { modification }\end{array}$} & $\begin{array}{l}\text { Small molecule } \\
\text { modification }\end{array}$ & Pulp & Promoted the preparation of nanocellulose & {$[93]$} \\
\hline & Graft modification & $\begin{array}{l}\text { Softwood cellulose } \\
\text { fiber }\end{array}$ & Formed a strong nanocomposite & {$[94]$} \\
\hline & Cross-linking modification & Cellulose nanocrystals & $\begin{array}{l}\text { Improved thermal stability and water } \\
\text { resistance, decreased swelling degree }\end{array}$ & {$[95]$} \\
\hline \multirow{2}{*}{$\begin{array}{l}\text { Biological } \\
\text { modification }\end{array}$} & In situ modification & $\begin{array}{l}\text { 6-Carboxyfluorescein- } \\
\text { modified glucose }\end{array}$ & $\begin{array}{l}\text { With nonnatural characteristic fluorescent } \\
\text { function }\end{array}$ & {$[96]$} \\
\hline & Ex situ modification & $\begin{array}{l}\text { Proanthocyanidins as } \\
\text { cross-linking agent }\end{array}$ & Novel bacterial cellulose/gelatin composite & $\begin{array}{l}{[97,} \\
98]\end{array}$ \\
\hline
\end{tabular}

with mineral admixtures significantly reduces the content of calcium hydroxide, avoids the deterioration of fiber performance, and ensures the strength and toughness of cementbased composites [82]. More studies revealed that it can produce cementitious materials without calcium hydroxide by using calcined metakaolin and calcined waste crushed clay bricks instead of ordinary Portland cement [53].

There are many types of supplementary cementitious materials used, and the extent of improvement varies. As shown in Table 5, the abbreviations of each component are as follows: silica fume (SF), blast furnace slag (SL), fly ash (FA), metakaolin (MK), rice husk ash (RHA), natural rubber latex (NRL), nanoclay (NC), gypsum (GY), and lime (LI).

4.3.2. Modification of CFs. Improving the water resistance of CFs and the adhesion between the matrix and the fiber interface is a necessary method to develop composites with good mechanical and environmental properties. However, the various types of CFs, geographical and climatic conditions, and growth cycles make the performance of CFs different. Some CFs have poor chemical resistance and low strength. These fibers can be modified to improve their internal and external structures and mechanical performance. The modification of CFs mainly includes physical modification, chemical modification, and biological modification, among which chemical modification is the most common [87-90], as shown in Table 6.

In the modification method of cellulose, the physical method is simple, convenient, and easy to operate, but the performance of the modified product is unstable, and the modifier is easy to fall off from the cellulose, resulting in product performance reduction. The chemical method is a better modification method [91, 92]. Compared with small molecule modification, graft polymerization has obvious advantages. It imparts other properties to cellulose without changing the properties of cellulose, and the modification effect is very stable. However, there are also disadvantages such as difficulty in operation and difficulty in controlling the reaction [93-95]. The biological modification to cellulose should be modified in situ or ex situ according to the actual situation [96-98].

The fibers are chemically modified to remove hemicellulose, lignin, pectin, and other substances on its surface so that 
the structure of CFs becomes fibrillation and, which have a relatively rough appearance. The cement matrix interface forms a mechanical interlocking morphology [99-101].

When eucalyptus fibers are modified with 3mercaptopropyltrimethoxysilane [102], it is found that the fiber reduces the water retention and meanwhile improves the dimensional stability of the composite. Through the dry-wet cycle treatment of abaca, agave, and sisal fibers [103], the cross-section of the fiber is reduced, Young's modulus is increased, and the tensile strength and tensile strain are reduced. At the same time, the cavity becomes thinner. The modified fibers increase the interfacial shear strength of the cement-based composite and also improve the durability. By adding 5\% styrene-acrylic copolymer for treatment, after 200 dry and wet cycles, the water absorption ratio of the test piece is reduced by $50 \%$, the elastic modulus value is reduced by $40 \%$, and the shrinkage rate is reduced by $15 \%$, which improves the stiffness and dimensional stability of the specimen [104]. After the modification treatment, the interface between the fibers and the cement matrix forms a dense and cohesive transition zone, which makes the fiber adhere to the cement surface to prevent the fiber from mineralizing.

4.3.3. Multitype CFs. Macroscale CFs are of large diameter and cavity, so they will absorb water and swell in the initial stage of mixing with the cement matrix. In the later stage of cement hydration, the fiber moisture gradually loses, the fiber shrinks and collapses in the matrix interface, and some voids are left at the fiber and cement matrix interface, which affects the performance of the composite, as shown in Figure 4(b). In order to improve this situation, the acid hydrolysis method can be used to prepare micron-sized microcrystalline CFs and nanosized nanocrystalline CFs $[105,106]$.

Microcrystalline CF is super absorbent, which can supplement the lack of moisture in the cement matrix at the later stage of hydration so that the cement matrix can be fully hydrated. A large amount of cement hydration gel can be induced around the microcrystalline CFs in the cement matrix to fill the microcracks and voids of the matrix and reduce the dry shrinkage cracks of the cement matrix at the initial stage of hydration. Nanocrystalline CF is of the same size as the cement hydration gel, which can induce the cement matrix hydration $\mathrm{C}-\mathrm{S}-\mathrm{H}$ gel to adhere to the surface of the nanocrystalline CFs, so they are connected and fused to form a uniform continuous $\mathrm{C}-\mathrm{S}-\mathrm{H}$ gel phase in the cement matrix. The cement matrix hydrate can completely embed in the nanocrystalline CFs, avoiding the negative effects of volume instability caused by macroscale CFs and microcrystalline CFs, and can further improve the durability of the composite, as shown in Figure 4(c). The shrinkage rate and mechanical properties of the material have been improved by using micro-nano-microcrystalline cellulose to toughen the concrete $[107,108]$. Compared with ordinary samples, the network structure formed by the multitype fibers can transmit and share the stress generated by the plastic shrinkage of the cement matrix. The combination of the fiber and the matrix improved the crack resistance of the material and also enhanced its durability.

\section{Conclusions}

When microcracks appear during the service period of cement-based composites, the fibers share the load through the bridging action, which slows down the continuous development of the microcracks and increases the durability of the composites. The main conclusions are as follows.

The hydrophilicity and unique hollow structure of CFs optimize the pore structure of cement-based composites, so CFs can significantly improve the permeability, frost resistance, and carbonization resistance of CFCCs.

CFs uniformly dispersed in the cement matrix, and it can induce the orderly growth of cement hydration products at the initial stage of hydration and enhance the compactness of the cement matrix.

The internal curing characteristics of CFs on the cement matrix can enhance the durability of CFCCs. The utilization of microcrystalline CFs and nanocrystalline CFs has further improved the durability of CFCCs.

Cementitious materials with low alkali corrosion have been used to reduce the long-term performance degradation of CFs, such as magnesium silicate cement, magnesium phosphate cement, and geopolymer cement.

Fiber modification is an important measure to improve the durability of CFCCs, and in particular, chemical modification has been usually used.

\section{Data Availability}

All underlying data are provided in full within this paper.

\section{Disclosure}

The funders had no role in the design of the study; in the collection, analyses, or interpretation of data; in the writing of the manuscript; or in the decision to publish the results.

\section{Conflicts of Interest}

The authors declare no conflict of interest.

\section{Acknowledgments}

This research was funded by the "General items of basic scientific research business expenses of provincial universities in Heilongjiang Province" (grant number "135409313") and "Heilongjiang Province Higher Education Teaching Reform Project” (grant number "SJGY20200784”).

\section{References}

[1] A. K. Pandey, T. Pal, R. Sharma, and K. K. Kar, "Study of matrix-filler interaction through correlations between structural and viscoelastic properties of carbonous-filler/polymermatrix composites," Journal of Applied Polymer Science, vol. 137, no. 27, pp. 48660-48660, 2020.

[2] F. Pacheco-Torgal and S. Jalali, "Cementitious building materials reinforced with vegetable fibres: a review," Construction and Building Materials, vol. 25, no. 2, pp. 575-581, 2010. 
[3] A. M. Mohamed, M. H. Osman, H. Smaoui, and M. A. M. Ariffin, "Durability and microstructure properties of concrete with arabic gum biopolymer admixture," Advances in Civil Engineering, vol. 2018, pp. 1-9, 2018.

[4] O. Karahan and C. D. Atis, "The durability properties of polypropylene fiber reinforced fly ash concrete," Materials and Design, vol. 32, no. 2, pp. 1044-1049, 2011.

[5] I. Ahmad, P. Y. Wong, and I. Abdullah, "Effects of fiber composition andgraft-copoly(ethylene/maleic anhydride) on thermoplastic natural rubber composites reinforced by aramid fiber," Polymer Composites, vol. 27, no. 4, pp. 395-401, 2006.

[6] J. Zhu, J. Wei, Q. Yu, M. Xu, and Y. Luo, "Hybrid effect of wollastonite fiber and carbon fiber on the mechanical properties of oil well cement pastes," Advances in Materials Science and Engineering, vol. 2020, pp. 1-9, 2020.

[7] P. Agnihotri, S. Basu, and K. K. Kar, "Effect of carbon nanotube length and density on the properties of carbon nanotube-coated carbon fiber/polyester composites," Carbon, vol. 49, no. 9, pp. 3098-3106, 2011.

[8] R. Kumar, K. K. Kar, and K. Dasgupta, "Enhanced electrical, mechanical, and viscoelastic properties of carbon-carbon composites using carbon nanotubes coated carbon textile as reinforcement," Journal of Composite Materials, vol. 55, no. 13, pp. 1733-1748, 2021.

[9] A. Rahaman and K. K. Kar, "E-glass fibers coated with nickel phosphorous by electroless deposition technique," Composite Interfaces, vol. 23, no. 7, pp. 689-699, 2016.

[10] A. Rahaman and K. K. Kar, "Carbon nanomaterials grown on E-glass fibers and their application in composite," Composites Science and Technology, vol. 101, no. 12, pp. 1-10, 2014.

[11] A. K. Mohanty, S. Vivekanandhan, J.-M. Pin, and M. Misra, "Composites from renewable and sustainable resources: challenges and innovations," Science, vol. 362, no. 6414, pp. 536$542,2018$.

[12] S. Venkatarajan and A. Athijayamani, "An overview on natural cellulose fiber reinforced polymer composites," Materials Today: Proceedings, vol. 37, no. 2, pp. 3620-3624, 2021.

[13] H. Choi and Y. C. Choi, "Setting characteristics of natural cellulose fiber reinforced cement composite," Construction and Building Materials, vol. 271, no. 15, p. 121910, 2021.

[14] M. Sargaphuti, S. P. Shah, and K. D. Vinson, "Shrinkage cracking and durability characteristics of cellulose fiber reinforced concrete," Materials Journal, vol. 90, no. 4, pp. 309318, 1993.

[15] Ö. Andiç-Çakir, M. Sarikanat, H. B. Tüfekçi, C. Demirci, and U. H. Erdogan, "Physical and mechanical properties of randomly oriented coir fiber- cementitious composites," Composites Part B Engineering, vol. 61, no. 5, pp. 49-54, 2014.

[16] H. Savastano, S. F. Santos, M. Radonjic, and W. O. Soboyejo, "Fracture and fatigue of natural fiber-reinforced cementitious composites," Cement and Concrete Composites, vol. 31, no. 4, pp. 232-243, 2009.

[17] A. Sellami, M. Merzoud, and S. Amziane, "Improvement of mechanical properties of green concrete by treatment of the vegetals fibers," Construction and Building Materials, vol. 47 , no. 10, pp. 1117-1124, 2013.

[18] X. Liu, J. Li, F. Li, J. Wang, and H. Lu, "Study on the properties of an ecotype mortar with rice husks and sisal fibers," Advances in Civil Engineering, vol. 2021, Article ID 5513303, pp. 1-11, 2021.
[19] J. M. Ferraz, C. H. S. del Menezzi, M. R. Souza, E. Y. A. Okino, and S. A. Martins, "Compatibility of pretreated coir fibres (Cocos nucifera L.) with Portland cement to produce mineral composites," International Journal of Polymer Science, vol. 2012, no. 9, Article ID 290571, 7 pages, 2012.

[20] G. Ramakrishna and T. Sundararajan, "Impact strength of a few natural fibre reinforced cement mortar slabs: a comparative study," Cement and Concrete Composites, vol. 27, no. 5, pp. 547-553, 2004.

[21] M. A. S. Mohamed, E. Ghorbel, and G. Wardeh, "Valorization of micro-cellulose fibers in self-compacting concrete," Construction and Building Materials, vol. 24, no. 12, pp. 2473-2480, 2010.

[22] H. Ez-zaki, L. Riva, M. Bellotto et al., "Influence of cellulose nanofibrils on the rheology, microstructure and strength of alkali activated ground granulated blast-furnace slag: a comparison with ordinary Portland cement," Materials and Structures, vol. 54, no. 1, p. 23, 2021.

[23] S. Beck-Candanedo, M. Roman, and D. G. Gray, "Effect of reaction conditions on the properties and behavior of wood cellulose nanocrystal suspensions," Biomacromolecules, vol. 6, no. 2, pp. 1048-1054, 2005.

[24] H. Xu, Z. Shao, Z. Wang et al., "Experimental study on mechanical properties of fiber reinforced concrete: effect of cellulose fiber, polyvinyl alcohol fiber and polyolefin fiber," Construction and Building Materials, vol. 261, no. 20, p. 120610, 2020.

[25] M. Şahmaran and V. C. Li, "Durability properties of microcracked ECC containing high volumes fly ash," Cement \& Concrete Research, vol. 39, no. 11, pp. 1033-1043, 2009.

[26] D. Romanzini, H. L. Ornaghi Jr., S. C. Amico, and A. J. Zattera, "Influence of fiber hybridization on the dynamic mechanical properties of glass/ramie fiber-reinforced polyester composites," Journal of Reinforced Plastics and Composites, vol. 31, no. 23, pp. 1652-1661, 2012.

[27] M. Ardanuy, J. Claramunt, and R. D. Toledo Filho, "Cellulosic fiber reinforced cement-based composites: a review of recent research," Construction and Building Materials, vol. 79, no. 3, pp. 115-128, 2015.

[28] A. Balea, E. Fuente, M. C. Monte, Á. Blanco, and C. Negro, "Fiber reinforced cement based composites," Fiber Reinforced Composites579-648.

[29] A. Sharma, M. Thakur, M. Bhattacharya, T. Mandal, and S. Goswami, "Commercial application of cellulose nanocomposites - a review," Biotechnology Reports, vol. 21, no. 3, article e00316, 2019.

[30] D. Lasrado, S. Ahankari, and K. Kar, "Nanocellulose-based polymer composites for energy applications-a review," Journal of Applied Polymer Science, vol. 137, no. 27, pp. 4895948959, 2020.

[31] S. Mohan, E. Francis, S. Thomas, and N. Ninan, Natural Polymers, Biopolymers, Biomaterials, and Their Composites, Blends, and IPNs, Apple Academic Press, 1st edition, 2012.

[32] G. Tonoli, S. F. Santos, A. P. Joaquim, and H. Savastano Jr., "Effect of accelerated carbonation on cementitious roofing tiles reinforced with lignocellulosic fibre," Construction and Building Materials, vol. 24, no. 2, pp. 193-201, 2010.

[33] H. Kargarzadeh, M. Mariano, D. Gopakumar et al., "Advances in cellulose nanomaterials," Cellulose, vol. 25, no. 4, pp. 2151-2189, 2018. 
[34] I. Hamawand, S. Seneweera, P. Kumarasinghe, and J. Bundschuh, "Nanoparticle technology for separation of cellulose, hemicellulose and lignin nanoparticles from lignocellulose biomass: a short review," Nano-Structures \& Nano-Objects, vol. 24, no. 10, p. 100601, 2020.

[35] S. K. Singh, M. J. Akhtar, and K. K. Kar, "Hierarchical carbon nanotube-coated carbon fiber: ultra lightweight, thin, and highly efficient microwave absorber," ACS Applied Materials \& Interfaces, vol. 10, no. 29, pp. 24816-24828, 2018.

[36] A. K. Bledzki and J. Gassan, "Composites reinforced with cellulose based fibres," Progress in Polymer Science, vol. 24, no. 2, pp. 221-274, 1999.

[37] W. Jing, Z. Weijun, and W. Luoxin, "Effect of submicron cellulosic fiber on the micro-structure of cement paste," Journal of Building Materials, vol. 21, no. 2, pp. 309-313, 2018.

[38] Y. A. Mubarak, "Tensile and impact properties of microcrystalline cellulose nanoclay polypropylene composites," International Journal of Polymer Science, vol. 2018, Article ID 1708695, 13 pages, 2018.

[39] J. d. A. Melo Filho, F. d. A. Silva, and R. D. Toledo Filho, "Degradation kinetics and aging mechanisms on sisal fiber cement composite systems," Cement and Concrete Composites, vol. 40, no. 7, pp. 30-39, 2013.

[40] W. Yong, S. Huijuan, and X. Shaoxiang, "Study on properties of polyurea/acrylic resin composite film reinforced by nanocrystalline cellulose," Materials Review, vol. 29, no. 6, pp. 11-14, 2015.

[41] P. Klemm, F. Kramer, S. Moritz et al., "Nanocelluloses: a new family of nature-based materials," Angewandte Chemie International Edition, vol. 50, no. 24, pp. 5438-5466, 2011.

[42] F. D. A. Silva, B. Mobasher, C. Soranakom, and R. D. T. Filho, "Effect of fiber shape and morphology on interfacial bond and cracking behaviors of sisal fiber cement based composites," Cement and Concrete Composites, vol. 33, no. 8, pp. 814-823, 2011.

[43] B. He, L. Xie, Q. Liu, and S. Zhang, "Influence of fiber hydrophilic to improve the frost resistance of concrete," Journal of Sichuan University (Engineering Science Edition), vol. 48, no. 2, pp. 225-230, 2016.

[44] Q. Hongping, "Experimental study and engineering application of anti-cracking and impermeability performance of concrete mixed with cellulose fiber and hybrid fiber," New Building Materials, vol. 39, no. 3, pp. 40-42, 2012.

[45] Y. J. Li and J. Jian, "Experimental study on anti-permeability of cellulose fiber and hybrid fiber concrete," Advanced Materials Research, vol. 482, no. 484, pp. 1334-1337, 2012.

[46] J. Wei, S. Ma, and D.'. S. G. Thomas, "Correlation between hydration of cement and durability of natural fiber- reinforced cement composites," Corrosion Science, vol. 106, no. 5, pp. 1-15, 2016

[47] M. Nili, A. Azarioon, A. Danesh, and A. Deihimi, "Experimental study and modeling of fiber volume effects on frost resistance of fiber reinforced concrete," International Journal of Civil Engineering, vol. 16, no. 3, pp. 263-272, 2016.

[48] C. Li, J. Hu, C. Yuan, and G. Yu, "Experimental study on the freezing resistance of fiber reinforced high strength concrete," Acta Materiae Compositae Sinica, vol. 36, no. 8, pp. 19771983, 2019.

[49] P. Soroushian, J.-P. Won, and M. Hassan, "Durability characteristics of $\mathrm{CO}_{2}$-cured cellulose fiber reinforced cement com- posites," Construction and Building Materials, vol. 34, no. 9, pp. 44-53, 2012.

[50] G. Ramakrishna, T. Sundararajan, and S. Kothandaraman, "Evaluation of durability of natural fibre reinforced cement mortar composite- a new approach," Journal of Engineering \& Applied Sciences, vol. 5, no. 6, 2010.

[51] L. Guo, W. Zhang, W. Sun, Z. Shen, and C. Ding, "Durability of cellulose fiber reinforced concrete under bending load in tunnel engineering," Journal of Southeast University (Natural Science Edition), vol. 46, no. 3, pp. 612-618, 2016.

[52] V. M. John, M. A. Cincotto, C. Sjöström, V. Agopyan, and C. T. A. Oliveira, "Durability of slag mortar reinforced with coconut fibre," Cement and Concrete Composites, vol. 27, no. 5, pp. 565-574, 2004.

[53] J. Wei and C. Meyer, "Utilization of rice husk ash in green natural fiber-reinforced cement composites: mitigating degradation of sisal fiber," Cement and Concrete Research, vol. 81, no. 3, pp. 94-111, 2016.

[54] B. J. Mohr, H. Nanko, and K. E. Kurtis, "Durability of kraft pulp fiber-cement composites to wet/dry cycling," Cement and Concrete Composites, vol. 27, no. 4, pp. 435-448, 2005.

[55] B. J. Mohr, H. Nanko, and K. E. Kurtis, "Durability of thermomechanical pulp fiber-cement composites to wet/dry cycling," Cement and Concrete Composites, vol. 35, no. 8, pp. 1646-1649, 2005.

[56] J. Wei and C. Meyer, "Degradation mechanisms of natural fiber in the matrix of cement composites," Cement and Concrete Research, vol. 73, pp. 1-16, 2015.

[57] J. Wei and C. Meyer, "Sisal fiber-reinforced cement composite with Portland cement substitution by a combination of metakaolin and nanoclay," Journal of Materials Science, vol. 49, no. 21, pp. 7604-7619, 2014.

[58] G. A. Holt, P. Chow, J. D. Wanjura, M. G. Pelletier, and T. C. Wedegaertner, "Evaluation of thermal treatments to improve physical and mechanical properties of bio-composites made from cotton byproducts and other agricultural fibers," Industrial Crops \& Products, vol. 52, no. 1, pp. 627-632, 2014.

[59] A. A. Belkadi, S. Aggoun, C. Amouri, A. Geuttala, and H. Houari, "Effect of vegetable and synthetic fibers on mechanical performance and durability of metakaolin-based mortars," Journal of Adhesion Science and Technology, vol. 32, no. 15, pp. 1670-1686, 2018.

[60] L. Zhang, Z. Jiang, H. Wu et al., "Flexural properties of renewable coir fiber reinforced magnesium phosphate cement, considering fiber length," Materials, vol. 13, no. 17, pp. 3692-3692, 2020.

[61] F. d. A. Silva, D. Zhu, B. Mobasher, C. Soranakom, and R. D. Toledo Filho, "High speed tensile behavior of sisal fiber cement composites," Materials Science \& Engineering A, vol. 527, no. 3, pp. 544-552, 2009.

[62] P. J. C. Machado, R. A. dos Reis Ferreira, L. A. de Castro Motta, and D. Pasquini, "Characterization and properties of cementitious composites with cellulose fiber, silica fume and latex," Construction and Building Materials, vol. 257, no. 10, p. 119602, 2020.

[63] R. S. Teixeira, G. H. D. Tonoli, S. F. Santos et al., "Different ageing conditions on cementitious roofing tiles reinforced with alternative vegetable and synthetic fibres," Materials and Structures, vol. 47, no. 3, pp. 433-446, 2014.

[64] S. V. Bharathi, S. Vinodhkumar, and M. M. Saravanan, "Strength characteristics of banana and sisal fiber reinforced 
composites," IOP Conference Series Materials Science and Engineering, vol. 1055, no. 1, article 012024, 2021.

[65] M. Ardanuy, J. Clarmunt, and R. Filho, "Evaluation of durability to wet/dry cycling of cement mortar composites reinforced with nanofibrillated cellulose," Brittle Matrix Composites, vol. 10, pp. 33-41, 2012.

[66] N. H. El-Ashkar, B. Mohr, H. Nanko, and K. E. Kurtis, "Durability of pulp fiber-cement composites to wet/dry cycling," Advances in Building Technology, vol. 35, no. 8, pp. 233237, 2002.

[67] S. U. N. Jia-ying, "Frost resistance characteristics of fiber concrete," Journal of Building Materials, vol. 16, no. 3, pp. 437440, 2013.

[68] A. E. F. S. Almeida, G. H. D. Tonoli, S. F. Santos, and H. Savastano, "Improved durability of vegetable fiber reinforced cement composite subject to accelerated carbonation at early age," Cement and Concrete Composites, vol. 42, no. 9, pp. 49-58, 2013.

[69] A. F. Almeida, G. Tonoli, S. Santos, and H. S. Junior, "Accelerated carbonation in the early ages of cellulose pulps reinforced cement composites," Ambiente Construído, vol. 10, no. 4, pp. 233-246, 2010.

[70] J. Claramunt, M. Ardanuy, and L. J. Fernandez-Carrasco, "Wet/dry cycling durability of cement mortar composites reinforced with micro- and nanoscale cellulose pulps," BioResources, vol. 10, no. 2, 2015.

[71] V. da Costa Correia, S. F. Santos, and H. Savastano, "Vegetable fiber as reinforcing elements for cement based composite in housing applications - a Brazilian experience," MATEC Web of Conferences, vol. 149, p. 01007, 2018.

[72] Z. He, Y. Jia, and S. Wang, "Maximizing $\mathrm{CO}_{2}$ sequestration in cement-bonded fiberboards through carbonation curing," Construction and Building Materials, vol. 213, pp. 51-60, 2019.

[73] C. Dong, W. Sun, and N. Banthia, "Use of tomography to understand the influence of preconditioning on carbonation tests in cement-based materials," Cement and Concrete Composites, vol. 88, pp. 52-63, 2018.

[74] D. N. Winslow and S. Diamond, "A mercury porosimetry study of the evolution of porosity in portland cement," Gels, 1969.

[75] G. Ma, X. Zheng, and P. Guo, "Early-age cracking resistance and self-shrinkage behavior of recycled cellulose fibersreinforced cement mortar," Journal of Civil and Environmental Engineering, vol. 42, no. 3, pp. 127-132, 2020.

[76] K. Jiang, C. Qi, Y. Cui, T. Li, and Z. Lu, "Effects of several factors such as cellulose on the properties of polyethylene fiber reinforced pervious concrete," Materials Review, vol. 34, Supplement 1, pp. 189-192, 2020.

[77] G. Ma, N. M. Salman, L. Wang, and F. Wang, "A novel additive mortar leveraging internal curing for enhancing interlayer bonding of cementitious composite for 3D printing," Construction and Building Materials, vol. 244, no. 5, p. $118305,2020$.

[78] X. Xie, H. David, Z. Wang, X. Xu, and Z. Zuowan, "Cellulosic fibers from rice straw and bamboo used as reinforcement of cement- based composites for remarkably improving mechanical properties," Composites Part B Engineering, vol. 78, pp. 153-161, 2015.

[79] V. D. Pizzol, L. M. Mendes, L. Frezzatti, H. Savastano Jr., and G. H. D. Tonoli, "Effect of accelerated carbonation on the microstructure and physical properties of hybrid fibercement composites," Minerals Engineering, vol. 59, no. 5, pp. 101-106, 2014.

[80] R. Mac Vicar, L. M. Matuana, and J. J. Balatinecz, "Aging mechanisms in cellulose fiber reinforced cement composites," Cement and Concrete Composites, vol. 21, no. 3, pp. 189-196, 1999.

[81] R. M. de Gutiérrez, L. N. Díaz, and S. Delvasto, "Effect of pozzolans on the performance of fiber-reinforced mortars," Cement and Concrete Composites, vol. 27, no. 5, pp. 593598, 2004.

[82] G. H. D. Tonoli, A. P. Joaquim, M. A. Arsene, K. Bilba, and H. Savastano, "Performance and durability of cement based composites reinforced with refined sisal pulp," Materials and Manufacturing Processes, vol. 22, no. 2, pp. 149-156, 2007.

[83] R. D. Toledo Filho, F. D. A. Silva, E. M. R. Fairbairn, and J. D. A. M. Filho, "Durability of compression molded sisal fiber reinforced mortar laminates," Construction and Building Materials, vol. 23, no. 6, pp. 2409-2420, 2009.

[84] R. D. Tolêdo Filho, K. Ghavami, G. L. England, and K. Scrivener, "Development of vegetable fibre-mortar composites of improved durability," Cement and Concrete Composites, vol. 25, no. 2, pp. 185-196, 2003.

[85] B. J. Mohr, J. J. Biernacki, and K. E. Kurtis, "Supplementary cementitious materials for mitigating degradation of kraft pulp fiber-cement composites," Cement and Concrete Research, vol. 37, no. 11, pp. 1531-1543, 2007.

[86] V. Agopyan, H. Savastano, V. M. John, and M. A. Cincotto, "Developments on vegetable fibre-cement based materials in Sao Paulo, Brazil: an overview," Cement \& Concrete Composites, vol. 27, no. 5, pp. 527-536, 2005.

[87] S. Kalia, A. Dufresne, B. M. Cherian et al., "Cellulose-based bio- and nanocomposites: a review," International Journal of Polymer Science, vol. 2011, Article ID 837875, 35 pages, 2011.

[88] M. I. D. Dulmalik and S. N. Kumala, "The effect of $\mathrm{NaOH}$ concentration variation in the process of paper making from bamboo fiber," IOP Conference Series: Materials Science and Engineering, vol. 535, no. 1, 2019.

[89] J. Liu and C. Lv, "Synthesizing environmentally friendly nonsilicone oxygen bleaching stabilizer for linen yarn using oligomeric acrylic acid," Scientific Reports, vol. 11, no. 1, p. 10355, 2021.

[90] E. Yuanita, Y. A. Husnil, M. A. Mochtar, R. Lailani, and M. Chalid, "The effect of alkalization treatment on fibermatrix compatibility in natural fiber reinforced composite," Key Engineering Materials, vol. 847, no. 6, pp. 28-33, 2020.

[91] N. C. T. Martins, C. S. R. Freire, and R. J. B. Pinto, "Electrostatic assembly of Ag nanoparticles onto nanofibrillated cellulose for antibacterial paper products," Cellulose, vol. 19, no. 4, pp. 1425-1436, 2012.

[92] J. Majoinen, J. S. Haataja, and D. Appelhans, "Supracolloidal multivalent interactions and wrapping of dendronized glycopolymers on native cellulose nanocrystals," Journal of the American Chemical Society, vol. 136, no. 3, pp. 866-869, 2014.

[93] O. Nechyporchuk, M. N. Belgacem, and J. Bras, "Production of cellulose nanofibrils: a review of recent advances," Industrial Crops and Products, vol. 93, no. 11, pp. 2-25, 2016.

[94] C. Chuensangjun, T. Kitaoka, Y. Chisti, and S. Sirisansaneeyakul, "Optimal ring-opening polymerization 
for producing surface-modi-fied cellulose nanofibers-graftpoly(lactic acid) s," New Biotechnology, vol. 44s, no. 10, pp. s105-s105, 2018.

[95] H. Zhengzheng, T. Xiuzhi, J. Xue, W. Hongbo, and G. Weidong, "Preparation and properties of dialdehyde nanocellulose cross-linked polyvinyl alcohol membranes," Journal of Materials Science and Engineering, vol. 37, no. 4, pp. 578-582, 2019.

[96] M. Gao, J. Li, and Z. Bao, "A natural in situ fabrication method of functional bacterial cellulose using a microorganism," Nature Communications, vol. 10, no. 1, pp. 437-437, 2019.

[97] J. Wang, Y. Z. Wan, H. L. Luo, C. Gao, and Y. Huang, "Immobilization of gelatin on bacterial cellulose nanofibers surface via crosslinking technique," Materials Science \& Engineering $C$, vol. 32, no. 3, pp. 536-541, 2012.

[98] T. Almalkawi Areej and S. Parviz, "Aerated cement slurry and controlling fungal growth of low-cost biomass-based insulation materials," Scientific Reports, vol. 9, no. 1, p. 19237, 2019.

[99] A. Shahzad, "Effects of alkalization on tensile, impact, and fatigue properties of hemp fiber composites," Polymer Composites, vol. 33, no. 7, pp. 1129-1140, 2012.

[100] X. Xie, Z. Zhou, and Y. Yan, "Flexural properties and impact behaviour analysis of bamboo cellulosic fibers filled cement based composites," Construction and Building Materials, vol. 220, no. 9, pp. 403-414, 2019.

[101] X. Xie, G. Gou, and X. Wei, "Influence of pretreatment of rice straw on hydration of straw fiber filled cement based composites," Construction and Building Materials, vol. 113, no. 6, pp. 449-455, 2016.

[102] G. H. D. Tonoli, M. N. Belgacem, and G. Siqueira, "Processing and dimensional changes of cement based composites reinforced with surface-treated cellulose fibres," Cement and Concrete Composites, vol. 37, no. 3, pp. 68-75, 2013.

[103] M. Ardanuy and Claramunt, "Effect of water treatment on the fiber-matrix bonding and durability of cellulose fiber cement composites," Journal of Biobased Materials and Bioenergy, vol. 9, no. 5, pp. 486-492, 2015.

[104] E. O. Cruz, M. J. Radler, and M. Perello, "Fiber cement boards modified with styrene-acrylic copolymer: an approach to address dimensional stability and cellulose fiber preservation," Journal of Composite Materials, vol. 55, no. 3, pp. 437-452, 2021.

[105] A. Balea, E. Fuente, and A. Blanco, "Nanocelluloses: naturalbased materials for fiber-reinforced cement composites. A critical review," Polymers, vol. 11, no. 3, p. 518, 2019.

[106] S. Ahankari, T. George, A. Subhedar, and K. K. Kar, "Nanocellulose as a sustainable material for water purification," SPE Polymers, vol. 1, no. 2, pp. 69-80, 2020.

[107] T. Wenrui, M. Changwen, and D. Bei, "Properties study and mechanism analysis of concrete reinforced by microcrystalline cellulose," New Building Materials, vol. 37, no. 7, pp. 46, 2010.

[108] H.-J. Lee, S.-K. Kim, and H.-S. Lee, “A study on the drying shrinkage and mechanical properties of fiber reinforced cement composites using cellulose nanocrystals," International Journal of Concrete Structures and Materials, vol. 13, no. 1, pp. 1-11, 2019. 